\title{
Composição e distribuição dos Crustacea (Decapoda) na Lagoa do Peixe, Rio Grande do Sul, Brasil
}

\author{
Sandro Santos ${ }^{1}$ \\ Paulo Juarez Rieger ${ }^{2}$ \\ Roni Roberto Ramos Vieira ${ }^{3}$ \\ Roberta Araujo Barutot ${ }^{3}$
}

\begin{abstract}
Composition and distribution of Crustacea (Decapoda) from Lagoa do Peixe, Rio Grande do Sul, Brazil. The Lagoa do Peixe ("Peixe's Lagoon") is located between Atlantic Ocean and Lagoa dos Patos and is $30 \mathrm{Km}$ long and 0,5-2,0 $\mathrm{Km}$ wide $\left(31^{\circ} 13^{\prime} \mathrm{S}, 50^{\circ} 55^{\prime} \mathrm{W}-31^{\circ} 26^{\prime} \mathrm{S}, 51^{\circ} 09^{\prime}\right)$. For one year, the composition and distribution of Crustacea Decapoda were analyzed monthly (from July/1994 to June/1995), in seven subareas (terrestrial border and aquatic area) and physical and chemical parameters (depth, salinity, sediment texture, oxygen in water, organic material of sediment and water temperature) were registered. Decapoda from the families Grapsidae, Ocypodidae, Portunidae (Brachyura), Diogenidae (Anomura) and Penaeidae (Penaeidea) were captured. Chasmagnathus granulata Dana 1851 was found all months near the canal connecting Atlantic Ocean and Lagoa do Peixe, but inside the lagoon it was collected only in October/94 and June/95, and in extreme subareas it was sampled in February/95 when the salinity was $31 \%$ at these sites. Callinectes sapidus Rathbun, 1896 and Cyrtograpsus angulatus Dana, 1851 were captured throughout the year, except October/94 and April/95, respectively. Both species were found in all areas of sample, indicating a high plasticity in relation to the factors analyzed in this study. Another species captured probably come in the lagoon in specific months, when the environment provides ideal conditions for their developments.
\end{abstract}

KEY WORDS. Crustacea, Decapoda, Lagoa do Peixe, Rio Grande do Sul, Brazil

O litoral do Rio Grande do Sul estende-se por aproximadamente $620 \mathrm{Km}$, com uma superfície terrestre de cerca de $30.000 \mathrm{Km}^{2}$. Nessa área são encontradas cerca de 50 lagoas litorâneas. A maioria destas lagoas é alongada, paralela à praia e de pouca profundidade (RAMBO 1994).

Em 1986 foi criado, ao redor de uma dessas lagoas, o Parque Nacional da Lagoa do Peixe com uma área de 34 ha, abrangendo os municípios de São José do Norte, Tavares e Mostardas. Nessa área, são encontrados ambientes de banhados, campos, mata de restinga, dunas móveis, fixas, secas e úmidas. Como destaque do parque, a Lagoa do Peixe apresenta aproximadamente $30 \mathrm{Km}$ de comprimento, 0,5

1) Departamento de Biologia, CCNE, Universidade Federal de Santa Maria. $97105-900$ Santa Maria, Rio Grande do Sul, Brasil. E-mail: ssantos@ccne.ufsm.br

2) Laboratório de Zoologia de Crustáceos Decápodos, DCMB, Fundação Universidade do Rio Grande. 96100-900 Rio Grande, Rio Grande do Sul, Brasil. E-mail: dmbpjr@super.furg.br

3) Curso de Pós-Graduação em Ciências Biológicas, Área de Zoologia, Universidade Estadual Paulista. 18618-000 Botucatu, São Paulo, Brasil. 
a $2 \mathrm{Km}$ de largura e uma profundidade média da ordem de $0,5 \mathrm{~m}$. A lagoa se comunica com o mar através de um canal situado próximo do seu comprimento médio. Essa comunicação faz com que a lagoa apresente águas salobras, ideais para o desenvolvimento de muitos organismos como siris, camarões, peixes e aves.

Embora seja um parque nacional, a área é ocupada por balneários, projetos de reflorestamento por Pinus, plantações de arroz, cebola, pecuária extensiva e por pescadores. Todas essas atividades devem interferir na dinâmica desse ecossistema.

Em 1989 a Fundação Universidade do Rio Grande (FURG) firmou um convênio com o Instituto Brasileiro do Meio Ambiente e Recursos Naturais Renováveis (IBAMA), visando desenvolver trabalhos na região do parque, que auxiliassem no entendimento da dinâmica deste ecossistema.

Em uma lista preliminar sobre a fauna local, foram citadas 41 espécies de peixes, 6 de anfíbios, 12 de répteis, 138 de aves e 15 de mamíferos, encontradas no interior do parque, além de 66 espécies vegetais.

Em relação aos crustáceos estavam presentes camarões Penaeus (Farfantepenaeus) paulensis (Perez-Farfante, 1967) e siris (siri azul) Callinectes danae Smith, 1869. O camarão Penaeus ( $F$. paulensis é um dos principais produtos da pesca na Lagoa do Peixe e na sua captura, geralmente, são coletados outros crustáceos simpátricos.

Este trabalho tem como objetivos o levantamento das espécies de crustáceos decápodos da Lagoa do Peixe e a análise das distribuições espacial e sazonal dos mesmos, em função dos fatores ambientais salinidade, profundidade, teor de oxigênio dissolvido na água e textura do sedimento de fundo.

\section{MATERIAL E MÉTODOS}

A Lagoa do Peixe está localizada a $120 \mathrm{Km}$ ao norte do município de Rio Grande, Rio Grande do Sul, insere-se na Planície Litorânea do Rio Grande do Sul, uma região sedimentar conhecida também como "estreito", entre o Oceano Atlântico e a Lagoa dos Patos ( $31^{\circ} 13^{\prime} \mathrm{S}, 50^{\circ} 55^{\prime} \mathrm{W}$ a $\left.31^{\circ} 26^{\prime} \mathrm{S}, 51^{\circ} 09^{\prime} \mathrm{W}\right)$.

Os animais foram coletados mensalmente por um período de um ano (agosto/94 a julho/95), em sete áreas distintas no interior da lagoa, as quais foram definidas em uma coleta prévia, realizada em julho/94, em função, principalmente, do gradiente de salinidade que se estabelece entre a Barra e os extremos da lagoa: Área 1 -sul da lagoa, região de pastagem, profundidade média de $15 \mathrm{~cm}$ e salinidade de $1 \%$.

Área 2 - cerca $5 \mathrm{Km}$ ao sul da barra da lagoa; margem cercada por uma faixa estreita de pastagem seguida por dunas que se estendem até a praia; salinidade ao redor de $10 \%$ e profundidade média de 5 a $25 \mathrm{~cm}$.

Área 3 - barra da lagoa, canal que liga a lagoa ao Oceano Atlântico, nas duas margens há areia, sem vegetação, salinidade (na maré vazante) de $15 \%$ e profundidade média variando de $5 \mathrm{a} 100 \mathrm{~cm}$.

Área 4 - início da parte norte da lagoa, cerca de $500 \mathrm{~m}$ da barra, região marginal com vegetação características dos "Salt-Marsh", onde registrou-se uma salinidade de $17 \%$ nas poças que se formam e $13 \%$ na água do leito da lagoa, onde a profundidade registrada foi de $10 \mathrm{~cm}$. 
Área 5 - a $5 \mathrm{Km}$ ao norte da barra (frontal a região conhecida como Paiva); na margem há uma faixa com pastagem seguida por uma extensa área com pinheiros; salinidade de $10 \%$ e profundidade de 10 a $15 \mathrm{~cm}$.

Área 6 - a $10 \mathrm{Km}$ ao norte da barra, as características da margem são semelhantes às da área 5 , porém a salinidade registrada desta área foi de $1 \%$.

Área 7 - norte da lagoa, região conhecida como "Veia Terra"; a margem é cercada por pastagem, formando, em certas épocas do ano, um banhado; a salinidade registrada foi de $1 \%$ e a profundidade de $15 \mathrm{~cm}$.

Em todas as áreas foram realizadas, mensalmente, amostragens manuais em hábitat de margem, $1 \mathrm{~m}^{2}$ rente à água e outro cerca de $5 \mathrm{~m}$ afastado da água. Enquanto no leito da lagoa utilizou-se uma rede de "Coca" com $3 \mathrm{~m}$ de boca, $8 \mathrm{~m}$ de saco e malha de $15 \mathrm{~mm}$ entre nós, a qual foi arrastada por cerca de $100 \mathrm{~m}$ (cerca de 300 $\mathrm{m}^{2}$ de área amostrada). Além dos animais, em todos os locais de coleta foi tomada uma amostra de água para análise da temperatura, salinidade e teor de oxigênio, e uma amostra de sedimento para analisar a textura e o teor de matéria orgânica; no leito da lagoa, a profundidade de cada local também foi medida.

A temperatura foi medida com auxílio de um termômetro de mercúrio nos próprios locais de coleta. A salinidade foi estimada por meio de um refratômetro (salinômetro). O teor de oxigênio dissolvido na água foi determinado através do método de Winckler (GolTERMAN \& ClYMO 1969), modificado pela adição de azida sódica. $\mathrm{O}$ teor de matéria orgânica do sedimento foi determinado através do peso das cinzas livres.

A proporção entre as frações do sedimento (textura) foi determinada segundo a metodologia de WENTHWORTH (1922), ou seja, por peneiramento diferencial.

Para o estudo da distribuição, a presença dos animais de cada espécie, em cada local amostrado foi analisada em função das características físicas e químicas do ambiente (temperatura, salinidade, profundidade, teor de oxigênio dissolvido na água, textura do sedimento e teor de matéria orgânica), por meio de uma correlação linear de Pearson.

\section{RESULTADOS}

\section{Parâmetros físicos e químicos}

Durante o ano de estudo, a temperatura da água da lagoa variou de $10^{\circ} \mathrm{C}$ (julho/94) a $31^{\circ} \mathrm{C}\left(\right.$ dezembro/94), com média de $20,8^{\circ} \mathrm{C}\left( \pm 1,5^{\circ} \mathrm{C}\right)$.

As maiores salinidades foram registradas na área 3, média de $27,5 \%$ ( \pm $10,9)$, e as menores na área 7, média de 5,6 \% $( \pm 7,7)$.

Em relação ao teor de oxigênio dissolvido na água, as médias variaram de $8,42 \mathrm{mg} / \mathrm{l}( \pm 1,19)$ na área 7 , a $9,75 \mathrm{mg} / \mathrm{l}( \pm 2,12)$ na área 5 .

Em todas as áreas de coleta obteve-se material nas sete peneiras de fracionamento, porém na primeira, onde eram retidas as partículas com mais de $2,0 \mathrm{~mm}$ de diâmetro, a quantidade de material foi quase desprezível, variando de 0,04 a $0,3 \%$ do total do sedimento. Houve em todas as áreas um predomínio da fração "areia fina" (partículas de 0,125 a 0,250 mm de diâmetro). A menor porcentagem dessa fração, $64,3 \%$, foi encontrada na área 1 ; nas demais áreas a quantidade foi sempre 
superior a $70 \%$. Ainda em relação ao sedimento, o teor de matéria orgânica média variou de $0,50 \%( \pm 0,39)$ na área 3, a $1,29 \%( \pm 1,21)$ na área 1 .

$\mathrm{Na}$ área 4 foram verificadas as menores profundidades, média de $17,2 \mathrm{~cm}( \pm$ $11,7)$, enquanto que as maiores foram registradas nas áreas 2 e 3, 84,6 cm $( \pm 29,2)$ e $72,1 \mathrm{~cm}( \pm 32,9)$, respectivamente.

\section{Composição}

Ao todo, em um ano de estudo, foram capturados 6090 crustáceos decápodos, pertencentes a três infraordens, cinco famílias, nove gêneros e onze espécies, como segue abaixo:

\section{Penaeidea}

Penaeidae

Artemesia longinaris Bate, 1888

Penaeus (Farfantepenaeus) paulensis

\section{Anomura}

Diogenidae

Loxopagurus loxochelis (Moreira, 1901)

\section{Brachyura}

Grapsidae

Sesarminae

Chasmagnathus granulata Dana, 1851

Varuninae

Cyrtograpsus angulatus Dana, 1851
Ocypodidae

Ocypodinae

Uca (Celuca) uruguayensis Nobili, 1901

Ocypode quadrata (Fabricius, 1787)

Portunidae

Portuninae

Arenaeus cribrarius (Lamarck, 1818)

Callinectes bocourti A.M. Edwards, 1879

Callinectes danae Smith, 1869

Callinectes sapidus Rathbun, 1896

\section{Distribuição}

O caranguejo Cyrtograpsus angulatus e o camarão Penaeus ( $F$.) paulensis foram registrados em todas as áreas de amostragem no leito da lagoa. Nas tabelas I e II está representada a distribuição espacial e sazonal dos crustáceos decápodos amostrados.

Das onze espécies registradas, nove estavam presentes na área 3, sendo esta a área na qual foi coletado o maior número de espécimes, 2658. Na tabela I está representado o número de decápodos capturados em cada área de coleta.

Um maior número de indivíduos foi capturado nos meses de setembro a novembro, enquanto que de março a junho registraram-se os menores (Tab. II).

$\mathrm{Da}$ análise de correlação linear de Pearson, efetuada entre o número total de indivíduos capturados, de cada espécie, em cada área e as médias verificadas para os fatores ambientais, obteve-se correlação positiva significativa, ao nível de $5 \%$, entre Penaeus (F.) paulensis e a profundidade, Callinectes danae e o teor de oxigênio dissolvido na água e entre a fração de sedimento Areia Média com as espécies Cyrtograpsus angulatus, Callinectes danae, Ocypode quadrata e Artemesia longinaris (Tab. III).

Obteve-se correlações negativas significativas $(\mathrm{p}<0,05)$ entre a fração Silte-Argila com ermitão Loxopagurus loxochelis e entre o teor de matéria orgânica do sedimento e Callinectes danae (Tab. III). 
Tabela I. Distribuição espacial horizontal dos crustáceos decápodos capturados na Lagoa do Peixe, de julho/94 (prévia) a julho/95.

\begin{tabular}{|c|c|c|c|c|c|c|c|c|}
\hline \multirow{2}{*}{ Espécies } & \multicolumn{7}{|c|}{ Areas } & \multirow{2}{*}{ Total } \\
\hline & 1 & 2 & 3 & 4 & 5 & 6 & 7 & \\
\hline Cyrtograpsus angulatus & 20 & 253 & 2308 & 19 & 10 & 38 & 77 & 2725 \\
\hline Chasmagnathus granulata & 3 & 1186 & 37 & 1040 & 124 & 3 & 0 & 2393 \\
\hline Uca uruguayensis & 0 & 31 & 0 & 43 & 0 & 0 & 0 & 74 \\
\hline Ocypode quadrata & 0 & 9 & 0 & 0 & 0 & 0 & 0 & 9 \\
\hline Callinectes sapidus & 6 & 63 & 6 & 5 & 0 & 68 & 12 & 160 \\
\hline Callinectes danae & 1 & 23 & 57 & 3 & 37 & 4 & 0 & 125 \\
\hline Callinectes bocourti & 1 & 0 & 0 & 0 & 0 & 1 & 0 & 2 \\
\hline Arenaeus cribrarius & 0 & 0 & 6 & 0 & 0 & 4 & 0 & 10 \\
\hline Loxopagurus loxochelis & 0 & 0 & 1 & 1 & 0 & 0 & 0 & 2 \\
\hline Penaeus (F.) paulensis & 81 & 74 & 15 & 1 & 1 & 6 & 45 & 223 \\
\hline Artemesia longinaris & 0 & 0 & 367 & 0 & 0 & 0 & 0 & 367 \\
\hline Total & 112 & 1639 & 2797 & 1112 & 172 & 124 & 134 & 6090 \\
\hline
\end{tabular}

Tabela II. Distribuição sazonal dos crustáceos decápodos capturados na Lagoa do Peixe, de julho/94 (prévia) a julho/95.

\begin{tabular}{|c|c|c|c|c|c|c|c|c|c|c|c|c|c|c|}
\hline \multirow{2}{*}{ Espécies } & \multicolumn{13}{|c|}{ Meses } & \multirow{2}{*}{ - Total } \\
\hline & Jul. & Ago. & Set. & Out. & Nov. & Dez. & Jan. & Fev. & Mar. & Abr. & Mai. & Jun. & Jul. & \\
\hline Cyrtograpsus angulatus & 129 & 382 & 377 & 522 & 827 & 51 & 16 & 178 & 7 & 3 & 12 & 5 & 216 & 2725 \\
\hline Chasmagnathus granulata & 186 & 146 & 358 & 276 & 212 & 247 & 212 & 259 & 79 & 93 & 15 & 89 & 221 & 2393 \\
\hline Uca uruguayensis & 0 & 4 & 14 & 7 & 24 & 5 & 15 & 0 & 5 & 0 & 0 & 0 & 0 & 74 \\
\hline Ocypode quadrata & 0 & 0 & 0 & 0 & 0 & 0 & 0 & 0 & 2 & 0 & 4 & 3 & 0 & 9 \\
\hline Callinectes sapidus & 5 & 2 & 0 & 2 & 8 & 8 & 1 & 1 & 53 & 4 & 28 & 0 & 48 & 160 \\
\hline Callinectes danae & 0 & 0 & 0 & 0 & 0 & 0 & 3 & 20 & 17 & 41 & 27 & 16 & 1 & 125 \\
\hline Callinectes bocourti & 0 & 0 & 0 & 0 & 0 & 0 & 0 & 0 & 0 & 1 & 1 & 0 & 0 & 2 \\
\hline Arenaeus cribrarius & 0 & 0 & 0 & 0 & 0 & 0 & 1 & 0 & 9 & 0 & 0 & 0 & 0 & 10 \\
\hline Loxopagurus loxochelis & 0 & 1 & 0 & 0 & 0 & 0 & 0 & 0 & 0 & 0 & 0 & 1 & 0 & 2 \\
\hline Penaeus (F.) paulensis & 0 & 0 & 0 & 0 & 3 & 82 & 41 & 34 & 19 & 24 & 15 & 0 & 5 & 223 \\
\hline Artemesia longinaris & 0 & 0 & 0 & 0 & 0 & 0 & 367 & 0 & 0 & 0 & 0 & 0 & 0 & 367 \\
\hline Total & 320 & 535 & 749 & 807 & 1074 & 393 & 656 & 492 & 191 & 166 & 102 & 114 & 491 & 6090 \\
\hline
\end{tabular}

Tabela III. Resultados da análise de correlação linear de Pearson, efetuada entre o número total de indivíduos capturados, de cada espécie, em cada área e as médias verificadas para os fatores ambientais. (PROF) Profundidade, (OXI) oxigênio, (SAL) salinidade, (CASC) cascalho, (AMG) areia muito grossa, (AG) areia grossa, (AM) areia média, (AF) areia fina, (AMF) areia muito fina, (SleAR) silte e argila, (MO) matéria orgânica.

\begin{tabular}{|c|c|c|c|c|c|c|c|c|c|c|c|}
\hline Espécies & PROF & OXI & SAL & CASC & AMG & AG & $\mathrm{AM}$ & AF & AMF & SleAR & MO \\
\hline Cyrtograpsus angulatus & 0,53 & 0, & 0 & -0 & 0 & -0 , & 0 & 0,10 & -0 & 0,71 & $-0,08$ \\
\hline Chasmagnathus granulata & 0,13 & 0,16 & 0,61 & 0,24 & $-0,10$ & $-0,12$ & 5 & 0,26 & $-0,48$ & $-0,09$ & 0,08 \\
\hline Uca uruguayensis & $-0,08$ & 0,07 & 0,57 & 0,46 & 0,17 & 0,15 & 0,13 & 0,10 & $-0,49$ & $-0,14$ & 0,17 \\
\hline Ocypode quadrata & 0,44 & 0,53 & 0,45 & $-0,18$ & 0,01 & $-0,06$ & $0,90^{*}$ & 0,04 & $-0,42$ & $-0,74$ & $-0,58$ \\
\hline Callinectes sapidus & 0,48 & $-0,31$ & $-0,21$ & $-0,49$ & $-0,30$ & $-0,45$ & $-0,04$ & 0,55 & $-0,19$ & 0,16 & $-0,28$ \\
\hline Callinectes danae & 0,33 & $0,90^{*}$ & 0,65 & $-0,42$ & $-0,40$ & $-0,36$ & $0,78^{*}$ & 0,35 & $-0,46$ & $-0,68$ & $-0,76^{*}$ \\
\hline Callinectes bocourti & 0,0 & $-0,67$ & $-0,63$ & $-0,45$ & $-0,21$ & $-0,30$ & $-0,43$ & $-0,45$ & 2 & & 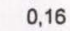 \\
\hline Arenaeus cribrarius & 0,38 & 0,30 & 0,14 & $-0,41$ & 0,04 & $-0,09$ & 0,74 & 0,23 & $-0,42$ & $-0,67$ & $-0,75$ \\
\hline Loxopagurus loxochelis & $-0,07$ & 0,43 & 0,64 & 0,41 & 0,45 & 0,41 & 0,75 & $-0,11$ & $-0,61$ & $-0,76^{*}$ & $-0,27$ \\
\hline Penaeus (F.) paulensis & $0,79^{*}$ & $-0,20$ & 0,02 & $-0,16$ & $-0,43$ & $-0,48$ & $-0,31$ & $-0,39$ & 0,57 & 0,46 & 0,59 \\
\hline Artemesia longinaris & 0,44 & 0,53 & 0,45 & $-0,18$ & 0,01 & $-0,06$ & $0,90^{*}$ & 0,04 & $-0,42$ & $-0,74$ & $-0,54$ \\
\hline
\end{tabular}

(*) Correlação significativa, $p<0,05$. 


\section{DISCUSSÃO}

Todos os anos, durante certo período, dezenas de pescadores procuram a Lagoa do Peixe para pescarem camarões jovens que procuram esta área durante uma fase de seu ciclo de vida. Junto com estes camarões são capturados vários outros crustáceos. A grande preocupação das autoridades locais do IBAMA é estabelecer o período apropriado para esta pesca, de forma a dar condições para que as populações se desenvolvam até um tamanho mínimo.

Os levantamentos faunísticos regionais são imprescindíveis para uma melhor compreensão da estrutura, funcionamento e variabilidade natural das comunidades, constituindo um requisito fundamental para o estabelecimento de programas de monitoração costeira (MORGADo \& AMARAL 1989). Tendo em vista a grande extensão da região litorânea do estado do Rio grande do Sul, a área representada pela Lagoa do Peixe é pequena, mas de grande importância como berçário para diversas espécies de crustáceos decápodos.

O litoral do Rio Grande do Sul caracteriza-se pela presença de ventos com velocidades médias entre três e sete nós (Carta DHN - 24.100). Embora sejam velocidades baixas, o fato de serem constantes acaba por afetar, marcantemente, vários dos fatores ambientais investigados neste trabalho, que por conseguinte podem influenciar na distribuição da fauna.

$\mathrm{O}$ vento movimenta a água, contribuindo para sua oxigenação e resultando em níveis sempre próximos do ponto de saturação. Como a profundidade média na lagoa é baixa, isto resulta em teores de oxigênio semelhantes, considerando-se profundidades similares.

A lagoa está em contato com a água salgada oceânica através do canal da barra. Com isto há uma tendência das áreas mais próximas à barra apresentarem médias de salinidade acima daquelas registradas nas extremidades. Mas o vento, dependendo da velocidade, pode contribuir para a dispersão das águas mais salinas, conduzindo-as até as extremidades.

O vento, mais uma vez, junto com a baixa profundidade, deve exercer grande influência no sedimento da Lagoa do Peixe, tornando a área homogênea em relação à sua textura, com o predomínio de areia fina em todas as áreas. Os resultados obtidos em relação ao teor de matéria orgânica do sedimento, segundo os padrões de MAGLIOCA \& KUTNER (1964), são baixos em todas as áreas.

No relatório final do projeto "Plano de Manejo do Parque Nacional da Lagoa do Peixe" cita-se a presença de grandes camarões Penaeus (Farfantepenaeus) paulensis e de grandes siris azuis Callinectes danae capturados através de uma rede de "coca tipo avião". Com este trabalho o número de crustáceos decápodos do parque é ampliado para 11 espécies.

ABELE (1974), estudando a diversidade de espécies de crustáceos decápodos em habitats marinhos, cita 14 espécies para os "salt marsh" com Spartina Schreb do noroeste da Flórida, E.U.A.. Segundo este autor, o número de espécies em habitats marinhos é proporcional à quantidade de substratos presentes na área. Assim, para esta região da Flórida foram identificados quatro tipos de substratos, campo com Spartina, local com Spartina morta, local com lama e área alagada 
(canal). Na Lagoa do Peixe, considerando-se as áreas com Spartina (2 e 4) além desses quatro tipos de substratos, também há locais de pastagem em suas adjacências. Embora tratando-se de regiões localizadas em hemisférios distintos, o número de espécies registradas nos dois estudos, para áreas com Spartina, são aproximados.

Novos estudos na Lagoa do Peixe poderão contribuir para aumentar este número de decápodos. Um grupo de carcinólogos estudando os Brachyura e Anomura, da Laguna de Términos no México, depois de mais de 14 anos de levantamento ainda vem acrescentando novas espécies à lista (RAZ-GUZMAN et al. 1992).

Trabalhos recentes vêm ampliando o limite de distribuição meridional de alguns Brachyura da costa sudeste-sul brasileira (BRANCO 1991; MELO 1996; RIEGER et al. 1996; SouZA 1997). Com este estudo foi ampliado o limite de distribuição de Callinectes bocourti, antes registrado até Santa Catarina.

Neste estudo foram capturados representantes das famílias Grapsidae, Ocypodidae e Portunidae (Brachyura), Diogenidae (Anomura) e Penaeidae (Penaeidea).

A família Grapsidae domina a região em número de exemplares coletados, $84 \%$ do total. Entre os animais desta família havia indivíduos juvenis e adultos, o que indica que passam todo o ciclo de vida na área, ao contrário das famílias Penaeidae $(9,7 \%)$ e Portunidae $(4,9 \%)$ das quais raramente se coletou animais adultos.

Chasmagnathus granulata, um caranguejo semi-terrestre, foi amostrado nas margens da lagoa em todos os meses de estudo nas áreas próximas ao canal que comunica a lagoa ao Atlântico, no entanto, no próprio canal esta espécie foi registrada somente nos meses de outubro/94 e junho/95 e, no extremo sul, em fevereiro/95, quando a aferição da salinidade indicou 31\%, naquela área. Esta espécie distribui-se no Atlântico Sul Ocidental: Brasil (do Rio de Janeiro até o Rio Grande do Sul), Uruguai e Argentina (Melo 1996). Na Lagoa do Peixe, a espécie é encontrada em regiões lamosas ou secas em tocas cujas profundidades variam em função do substrato, sempre associada com vegetação do tipo gramínea, como Spartina densiflora. BRANCO (1991) relata a presença desta espécie em desembocaduras de rios e riachos. É uma espécie adaptada à vida aérea, podendo permanecer horas exposta.

Callinectes sapidus e Cyrtograpsus angulatus foram capturados em quase todos os meses, com exceção de outubro/94 e abril/95, respectivamente, no leito da lagoa. Estas duas espécies foram as únicas a serem amostradas de um extremo ao outro da lagoa, inclusive no canal, indicando que apresentam uma grande plasticidade frente aos fatores ambientais analisados.

Cyrtograpsus angulatus distribui-se no Atlântico Sul ocidental: Brasil (do Rio de Janeiro até o Rio Grande do Sul), Uruguai, Argentina (incluindo a Patagônia); Pacífico oriental: Peru e Chile (MELo 1996). Na lagoa vivem, geralmente, em grandes concentrações, principalmente no canal que a liga ao Oceano. Em algumas ocasiões foram capturados fora da água, nas margens, próximo ao canal. Segundo MELO (1996) podem ser encontrados, também, sobre a vegetação das praias. 
Callinectes sapidus é um dos Brachyura mais amplamente distribuído pelo mundo, pode ser encontrado no Atlântico ocidental: em toda a costa leste dos Estados Unidos até a Flórida, Golfo do México, América Central, Antilhas, norte da América do Sul e Brasil (da Bahia ao Rio Grande do Sul), Atlântico Oriental, Mar do Norte, Mediterrâneo, Mar Adriático, Mar Negro e Indo-Pacífico (Japão). É capturado da faixa entre marés até $90 \mathrm{~m}$ de profundidade, mas na maioria das vezes ocorre em pequenas profundidades, em baías, estuários, lagoas e poças (MELO 1996). Raras vezes se capturou fêmeas adultas dessa espécie na lagoa, a maioria dos exemplares capturados eram imaturos e alguns machos adultos.

Vários estudos atribuem às espécies do gênero Callinectes a característica eurihalina, entre elas C. sapidus (CHURCHILL 1919; DEVRIES et al. 1983; PITA et al. 1985; BUCHANAN \& STONER 1988). Outra característica de C. sapidus, são as migrações entre ambientes com diferentes salinidades em função do ciclo reprodutivo da espécie (ENGEL 1958, 1990; BUCHANAN \& STONER 1988). Animais jovens tendem a se desenvolver em áreas estuarinas. Quando as fêmeas são copuladas pela primeira vez, migram para o alto mar onde irão nascer as larvas. Segundo BORGEOIS-LEBEL et al. (1982), entre os animais adultos, geralmente os machos toleram salinidades mais baixas do que as fêmeas, por isto essas últimas raramente são encontradas dentro de ambientes estuarinos.

Callinectes danae é outro portunídeo freqüentemente encontrado em estuários ou manguezais, com grande tolerância à salinidade, pode ser capturado do entre-marés até 75 m. Distribui-se no Atlântico Ocidental: Bermudas, Flórida, Golfo do México, América Central, Antilhas, norte da América do Sul, Brasil (da Paraíba até o Rio Grande do Sul) e Argentina (Melo 1996).

Segundo Melo (1996) Callinectes bocourti distribui-se no Atlântico Ocidental: Flórida, Golfo do México, Antilhas, Colômbia, Venezuela e no Brasil, do Pará até Santa Catarina. Com este estudo a distribuição dessa espécie é ampliado até o Rio Grande do Sul. Essa espécie geralmente é coletada em águas rasas ou salobras de estuários e desembocaduras de rios. Muitas vezes está associada a Callinectes sapidus. É encontrada em fundos de areia, lodo, rochas ou conchas, do entre-marés até 20 metros (MELO 1996; BRANCO 1991).

Arenaeus cribrarius é encontrado no Atlântico ocidental: Massachusetts até Carolina do Norte, Flórida, Golfo do México, América Central, Antilhas, norte da América do Sul, Brasil (do Ceará até o Rio Grande do Sul) e Uruguai. De acordo com MELo (1996) raramente essa espécie é encontrada em estuários ou lagoas. No leito da Lagoa do Peixe foram coletados somente jovens, nos meses de janeiro (1 indivíduo) e março (nove indivíduos), em locais onde a salinidade, nestes meses, variou de 32 a $34 \%$. Animais adultos dessa espécie podem ser capturados nas zonas de praia próximas à barra da lagoa. ABREU (1980) considera A. cribrarius como uma espécie eurihalina marinha, capaz de tolerar reduções de salinidade até $5 \%$. PINHEIRO et al. (1994), por sua vez, afirmam que $A$. cribrarius não tolera salinidades baixas e que a espécie, de acordo com seu levantamento, foi registrada numa faixa de 26,7 a 36,5\%. Nesse estudo, embora 10 animais tenham sido capturados no interior da lagoa, estas coletas ocorreram em períodos e locais onde a salinidade ficou dentro dos limites de tolerância citados por PINHEIRO et al. (1994). 
Ocypode quadrata foi amostrada nas dunas ao lado do canal da barra. Segundo MELo (1996) é encontrada na Flórida, Bermudas, Golfo do México, América Central, Antilhas, Norte da América do Sul, Guianas e Brasil (Pará até o Rio Grande do Sul, incluindo de Fernando de Noronha).

A outra espécie da família Ocypodidae, Uca (Celuca) uruguayensis distribui-se no Atlântico Ocidental: Bermudas, Flórida, Golfo do México, América Central, Antilhas, norte da América do Sul e Brasil (Bahia ao Rio Grande do Sul), Uruguai e Argentina; Atlântico Oriental: Cabo Verde até Angola, Mar do Norte, Mar Adriático, Mar Negro e Mar Mediterrâneo (Melo 1996). Foi capturada em pequenos bancos de areia na margem da lagoa.

Embora existam citações de anomuros para ambientes estuarinos, Loxopagurus loxochelis não havia sido registrado neste tipo de ambiente. A ocorrência desta espécie no leito das áreas $4 \mathrm{e} 3$, em agosto/94 e junho/95, respectivamente, provavelmente é ocasional. L. loxochelis distribui-se no Atlântico Ocidental: Brasil (da Bahia ao Rio Grande do Sul),Uruguai e Argentina (até Mar Del Plata) (RIEGER 1997).

Penaeus ( $F$.) paulensis é registrado no Atlântico ocidental: Brasil (Rio de Janeiro até o Rio Grande do Sul), Uruguai e Argentina (até Mar Del Plata) (CoELHO \& RAMOS 1972). A partir de outubro, as pós-larvas começam a ser capturadas no canal de acesso à lagoa, onde provavelmente entram para se desenvolver. Em novembro foram capturados animais com aproximadamente $50 \mathrm{~mm}$ de comprimento nas extremidades da lagoa.

Artemesia longinaris é encontrada no Atlântico ocidental: Brasil (Rio de Janeiro para o sul), Uruguai, Argentina (até Chubut) (COELHO \& RAMOS 1972). Na Lagoa do Peixe esta espécie foi capturada somente em janeiro/95, no leito da área 3 (canal da barra).

O número de espécies amostradas neste estudo pode ser considerado baixo, quando comparado com outros sistemas estuarinos brasileiros (ABREU 1980; BRANCo 1991; COBO et al. 1994; SANTOS et al. 1994). Isto provavelmente é decorrência das características físico-químicas, que devem selecionar consideravelmente a presença dos decápodos na área. Segundo ABELE (1974), ambientes de "SaltMarsh" com Spartina, embora com tipos diferentes de substratos são marcantemente caracterizados por aspectos terrestres, o que limita a colonização por decápodos marinhos.

Com este trabalho, o número de decápodos da lagoa do peixe é ampliado de duas para onze espécies. Muitas destas procuram a lagoa apenas numa fase de seu ciclo de vida, já que são amostradas apenas em alguns períodos do ano, como Penaeus (F.) paulensis.

Isto reforça o caráter de berçário da Lagoa do Peixe e justifica a preocupação das autoridades de controlar a pesca em seu interior.

Os meses e os locais propícios para o desenvolvimento de cada espécie também foram registrados, o que pode servir de subsídio para futuros estudos sobre a biologia e a monitoração daqueles decápodos. 
AGRADECIMENTOS. À Fundação de Amparo à Pesquisa do Estado do Rio Grande do Sul (FAPERGS) pelo auxílio financeiro (Proc. $\mathrm{n}^{\circ}$ 9560076-0). Ao Laboratório "Zoologia de Crustáceos Decápodos" - DCMB - FURG, pela infra-estrutura oferecida. Ao Instituto Brasileiro do Meio Ambiente e Recursos Naturais Renováveis (IBAMA) pela autorização de entrada e captura de animais na área do Parque Nacional da Lagoa do Peixe.

\section{REFERÊNCIAS BIBLIOGRÁFICAS}

ABELE, L.G. 1974. Species diversity of decapod crustaceans in marine habitats. Ecology 55: 156-161. ABREU, J. DE. 1980. Distribuição e ecologia dos Decapoda numa área estuarina de Ubatuba (SP). Bolm. Inst. Oceanogr. 29 (2): 1-3.

BourgeoIs-Lebel, S.; A. GuYARD \& M. Louis. 1982. Comportement migratoire des crabes du genre Callinectes (Crustacés, Décapodes, Portunidae) de la mangrove de Guadeloupe (Antilles françaises). Influence de la salinité. Acta Oecologica 3 (3): 339-352.

Branco, J.O. 1991. Aspectos ecológicos dos Brachyura (Crustacea, Decapoda) no manguezal do Itacorubi, SC - Brasil. Revta. bras. Zool. 7 (1-2): 165-179.

Buchanan, B A. \& A.W. Stoner. 1988. Distribution patterns of blue crabs (Callinectes sp.) in a tropical estuarine lagoon. Estuaries 11 (4): 231-239.

Cobo, V.J.; A. Fransozo; F.L.M. Mantelatto; M.A.A. Pinheiro; S. Santos \& J.M. Góes. 1994. Composição dos Braquiúros (Crustacea, Decapoda) no manguezal formado pelos rios Comprido e Escuro, Ubatuba, SP. Anais do III Simpósio de Ecossistemas da Costa Brasileira 1: 146-150.

CoElho, P.A. \& M.A. RAmos. 1972. A constituição e a distribuição da fauna de decápodos do litoral leste da América do Sul entre as latitudes de $5^{\circ} \mathrm{N}$ e $39^{\circ} \mathrm{S}$. Trab. Oceanogr. Univ. Fed. Pernambuco, Recife, 13: 133-236.

ChURCHILl, E.P. 1919. Life history of the blue crab. Bull. U.S. Bur. Fish. 36: 93-128.

DEVRIES, M.C.; C.E. EPIFANIO \& A.I. DITTEL. 1983. Reproduction periodicity of the tropical crab Callinectes arcuatus Ordway in Central America. Estuarine Coastal Shelf Sci. 17: 709-716.

ENGEL, W.A. VAN. 1958. The blue crab and its fishery in Chesapeake Bay. Part 1. Reproduction, early development, growth, and migration. Commer. Fish. Rev. 20 (6): 6-17.

1990. Development of the reproductively functional form in the male blue crab Callinectes sapidus. Bull. Mar. Sci. 46 (1): 13-22.

Golterman, H.L. \& R.S. Clymo. 1969. Methods for chemical analysis of freshwaters. Oxford, Blackwell Scientific Pub., 116p.

Maglioca, A. \& A.S. Kutner. 1964. Conteúdo orgânico dos sedimentos de fundo de Cananéia, SP. Contrib. Avulsas Inst. Oceanogr., São Paulo, 195: 1-15.

Melo, G.A.S. 1996. Manual de Identificação dos Brachyura (Caranguejos e Siris) do litoral brasileiro. São Paulo, Ed. Plêiade, Fapesp, 604p.

Morgado, E.H. \& A.C.Z. Amaral. 1989. Anelídeos poliquetos da região de Ubatuba (SP) - padrões de distribuição geográfica. Revta bras. Zool. 6 (3): 535-568.

Pinheiro, M.A.A.; A. Fransozo \& M.L. Negreiros-Fransozo. 1994. Distribution patterns of Arenaeus cribrarius (Lamarck, 1818) (Crustacea, Portunidae) in Fortaleza Bay, Ubatuba (SP), Brazil. Rev. Brasil. Biol. 56 (4): 705-716.

PitA, J.B.; E.S. Rodrigues; R. GraÇA-Lopes \& J.A.P. Coelho. 1985. Levantamento da família Portunidae (Crustacea, Decapoda, Brachyura) no complexo baía-estuário de Santos, SP, Brasil. Bol. Inst. Pesca, São Paulo, 12 (3): 153-162.

Rambo, B. 1994. A fisionomia do Rio Grande do Sul. São Leopoldo, Ed. Unisinos, $3^{a}$ ed., 473p.

RAZ-Guzman, A.; A.J. SÁnCHES \& L.A. Soto. 1992. Catálogo ilustrado de los cangrejos braquiuros y anomurus (Crustacea) de Laguna de Alvarado, Veracruz, México. México, Universidad Nacional Autónoma de México, Inst. de Biologia, 51p.

Rieger, P.J. 1997. Os "ermitões" (Crustacea, Decapoda, Parapaguridae, Diogenidae e Paguridae) do litoral do Brasil. Nauplius, São Paulo, 5, (2): 99-124.

Revta bras. Zool. 17 (1): 213 - 223, 2000 
Rieger, P.J.; R.R.R. Vieira \& S. SANTos. 1996. Hexapanopeus caribbaeus (Stimpson, 1871) novo registro de Brachyura (Crustacea, Xanthidae) para o litoral do Rio Grande do Sul, Brasil. Nauplius, Rio Grande, 4: 169-170.

Santos, S.; P.M. Souza; P. Góes \& C.M. Pegorer. 1994. Os Brachyura semiterrestres (Crustacea, Decapoda) de Ilha Comprida, SP, Brasil. Arq. Biol. Tecnol., Curitiba, 37 (2): 417-427.

SouZA, J.A.F. 1997. Brachyura da plataforma meridional do Rio Grande do Sul, Brasil (Crustacea, Decapoda). Nauplius 5 (2): 33-58.

Wenthworth, C.K. 1922. A scale of grade and class terms for clastic sediments. Jour. Geol. 30: 377-392.

Recebido em 03.IX.1998; aceito em 22.II.2000. 